\title{
Role of Color Doppler in the Diagnosis of Extracardiac Fetal Abnormalities
}

\author{
${ }^{1}$ TLN Praveen, ${ }^{2} \mathrm{P}$ Surekha \\ ${ }^{1}$ Consultant Radiologist, Abhishek's Institute of Imageology, Hyderabad, Andhra Pradesh, India \\ ${ }^{2}$ Professor and Head, Department of Radiology, Osmania Medical College, Niloufer Hospital, Hyderabad, Andhra Pradesh, India
}

Correspondence: TLN Praveen, Consultant Radiologist, Abhishek's Institute of Imageology, Plot No. 740-A, Road No. 37 Jubilee Hills, Hyderabad-500033, Andhra Pradesh, India, e-mail: tInpraveen@googlemail.com

\section{ABSTRACT}

Color Doppler is useful in evaluating fetal cardiac abnormalities and in assessing fetal hemodynamics in a hypoxic fetus. Color Doppler is extremely useful in evaluating extracardiac fetal abnormalities.

Keywords: Color Doppler, Fetal abnormalities, Extracardiac.

\section{INTRODUCTION}

Color Doppler conventionally plays important role in the diagnosis of cardiac abnormalities and hemodynamic response to hypoxia and anemia. There are various additional applications of color Doppler in the diagnosis of extracardiac fetal defects. Color Doppler in conjunction with three dimensional imaging helps in better evaluation of fetal vascular abnormalities and placental pathologies.

Following table briefly enumerates the role of color Doppler in evaluation of extracardiac abnormalities.

\begin{tabular}{|c|c|}
\hline Placenta & $\begin{array}{l}\text { - Placenta praevia } \\
\text { - Placenta accreta } \\
\text { - Placenta percreta } \\
\text { - Placenta increta } \\
\text { - Chorioangioma. }\end{array}$ \\
\hline Umbilical cord & $\begin{array}{l}\text { - Vasa praevia } \\
\text { - Nuchal cord } \\
\text { - False and true knots of the cord } \\
\text { - Short or long umbilical cord } \\
\text { - Hemangioma or angiomyxoma } \\
\text { of the cord } \\
\text { - Hypoplastic umbilical artery } \\
\text { - Single umbilical artery } \\
\text { - Varix or aneurysm of umbilical vein } \\
\text { - Abnormal course of umbilical vein } \\
\text { - Persistent right umbilical vein. }\end{array}$ \\
\hline Ductus venosus & - Absent ductus venosus. \\
\hline Monochorionic twins & $\begin{array}{l}\text { - Twin-to-twin transfusion syndrome } \\
\text { (TTTS) } \\
\text { - Twin reversed arterial perfusion } \\
\text { (TRAP) sequence } \\
\text { - Cord entanglement. }\end{array}$ \\
\hline
\end{tabular}

\begin{tabular}{|c|c|}
\hline Renal abnormalities & $\begin{array}{l}\text { - Unilateral or bilateral renal agenes } \\
\text { - Accessory renal vessels } \\
\text { - Horseshoe kidney } \\
\text { - Pelvic kidney. }\end{array}$ \\
\hline Intracranial vessels & $\begin{array}{l}\text { - Intracranial arteriovenous } \\
\text { malformations } \\
\text { - Abnormal course of the vessels } \\
\text { - Abnormal shape or distorted } \\
\text { "Circle of Willis". }\end{array}$ \\
\hline Thoracic lesions & $\begin{array}{l}\text { - Pulmonary hypoplasia } \\
\text { - Unilateral agenesis } \\
\text { - Right-sided diaphragmatic hernia } \\
\text { - Sequestrated lung. }\end{array}$ \\
\hline $\begin{array}{l}\text { Intra-abdominal } \\
\text { lesions }\end{array}$ & $\begin{array}{l}\text { - Omphalocele vs gastroschisis } \\
\text { - Polysplenia. }\end{array}$ \\
\hline Fetal tumors & $\begin{array}{l}\text { - Fetal goiter } \\
\text { - Renal vs suprarenal tumors } \\
\text { - Sacrococcygeal teratoma }\end{array}$ \\
\hline Fluid movement & $\begin{array}{l}\text { - Pulmonary hypoplasia } \\
\text { - Laryngeal atresia } \\
\text { - Duodenal stenosis } \\
\text { - Vesicoureteric reflux. }\end{array}$ \\
\hline Oligohydramnios & $\begin{array}{l}\text { - Premature rupture of membranes } \\
\text { - Renal agenesis } \\
\text { - IUGR. }\end{array}$ \\
\hline
\end{tabular}

\section{Placental and Umbilical Vessels}

- Placental abnormalities, such as placenta accreta, percreta and increta.

- Color Doppler helps in the diagnosis of chorioangioma, which is an arteriovenous malformation in the placenta. 


\section{Placenta Accreta (Fig. 1)}

- It is abnormal adherence of placenta to the uterus. The predisposing condition is previous cesarean section, and anterior placenta praevia. Other procedures, such as curettage and myomectomy also increase the risk.

- Placenta accreta results, when trophoblastic villi burrow into an area of poorly developed or absent decidua.

The abnormal placental attachments are:

- Accreta: Villi penetrate the decidua but not the myometrium.

- Increta: Villi penetrate and invade the myometrium but not the serosa.

- Percreta: Villi penetrate the myometrium and perforate the serosa.

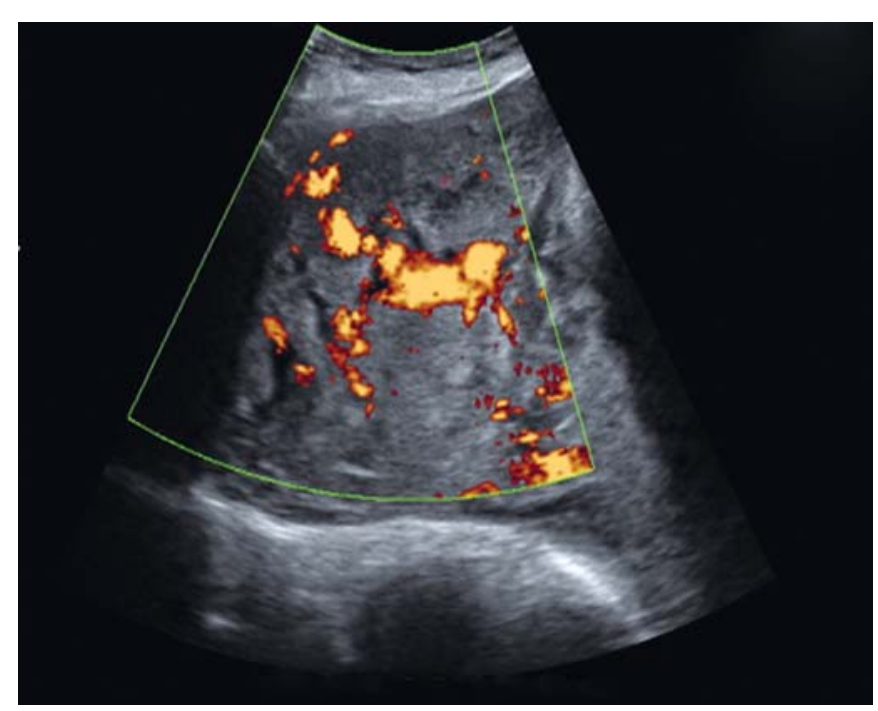

Fig. 1: Placenta previa with accreta

\section{Chorioangioma (Fig. 2)}

- It is a nontrophoblastic placental tumor

- Common benign neoplasm of the placenta

- Considered as hamartoma by some authors.

Sonographically appears as:

- Well-circumscribed

- Rounded, hypoechoic mass
- Occurring at the umbilical cord insertion site on the fetal surface of the placenta.

- Doppler shows abundant blood flow or large feeding vessels.

\section{Abnormalities of Umbilical Vessels}

- Vasa praevia

- Detection of nuchal cord

- False and true knots of the cord, length of the cordshort/long .

- Hemangioma or angiomyxoma of the cord

- Hypoplastic umbilical artery

- Fusion of two arteries into one

- Single umbilical artery

- Varix or aneurysm of intra-abdominal part of umbilical vein

- Abnormal course of umbilical vein, persistent right umbilical vein

- Absence of ductus venosus.

\section{Vasa Praevia (VP) (Fig. 3)}

Vasa praevia is a rare but clinically important condition, which can be diagnosed by color Doppler.

- Fetal vessels course over or close to cervix beneath the presenting part

- Unprotected by Wharton's jelly or placental tissue

- The vessels are vulnerable to laceration and compression, most commonly at the time of delivery.

\section{Implications}

- Fetal or neonatal death due to exsanguination or asphyxiation.

Risk factors (Doppler examination is recommended in these situations):

- Velamentous insertion of the cord (6\% associated with VP)

- Succenturiate lobe of placenta

- Placenta praevia

- Multiple gestation (10\% of VP occurs in twins)

- Amniotic bands

- IVF pregnancy (1:300).
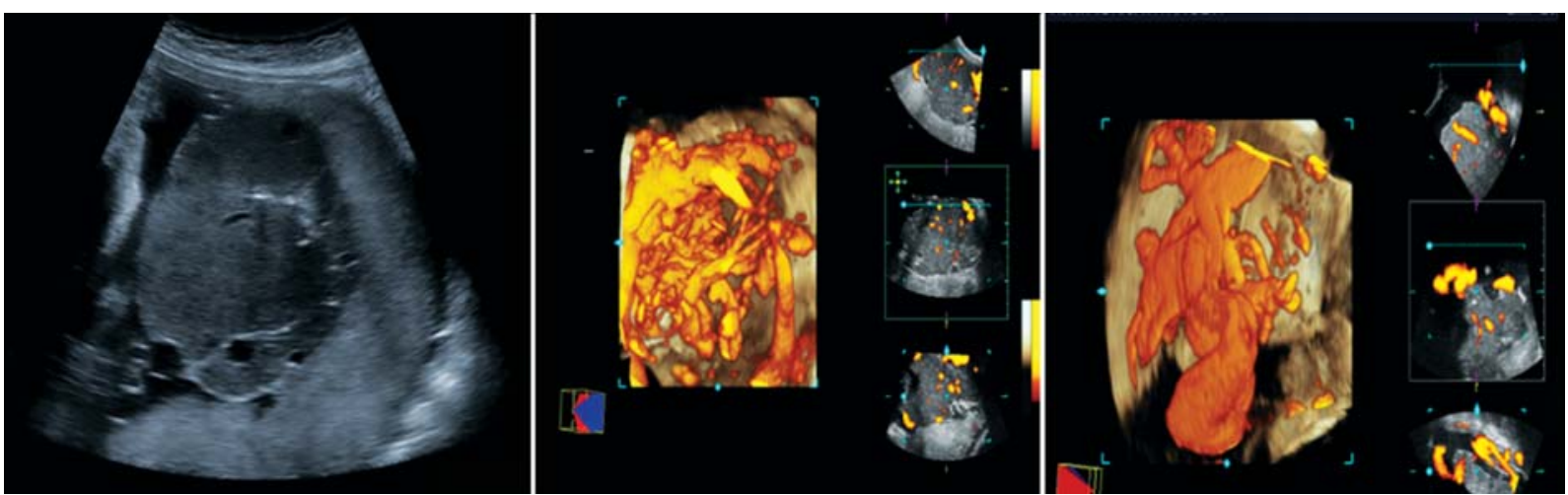

Fig. 2: Chorioangioma 


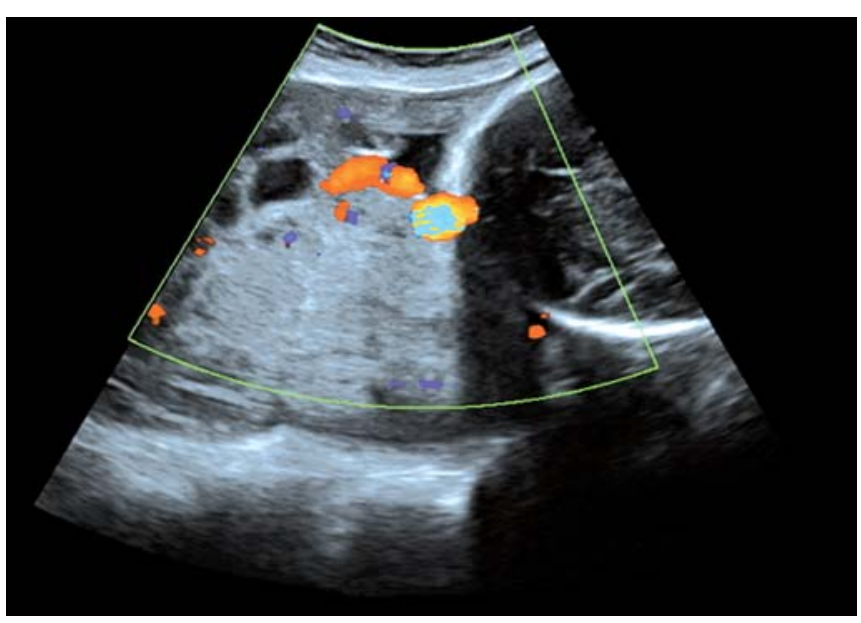

Fig. 3: Vasa previa

\section{Abnormalities of Umbilical Cord}

Normally the umbilical cord reaches a length of 55 to $70 \mathrm{~cm}$ at term.

\section{Short Umbilical Cord}

- Primarily due to failure of embryonic infolding.

- Secondary to decreased fetal movements due to central nervous system or musculoskeletal abnormalities, oligohydramnios, multiple gestation and breech presentation.

- Short cord may lead to cord compression, placental abruption and poor fetal descent during delivery.

- Short cord may be associated with congenital anomalies and trisomy 21.

\section{Long Umbilical Cord}

- May lead to cord knots, nuchal cord and cord prolapse.

- Knots of the umbilical cord are classified as true knots and false knots.

- True knots are common in monochorionic monoamniotic twins and rarely diagnosed on prenatal ultrasound.

- False knots are a misnomer. It is tortuous aggregation of dilated vessels with decreased covering by Wharton's jelly.

\section{Nuchal Cord (Fig. 4)}

- Nuchal cord appears as loops of cord posterior to the neck in the sagittal section and circumferentially around the neck in the axial section.

- Adverse fetal outcome is debatable and unclear.

- Searching for nuchal cord and reporting presence of nuchal cord is also debatable.

\section{Cord Coiling}

Ultrasound diagnosis of under coiling and hypercoiling of the cord is not reliable and has questionable impact on clinical outcome.

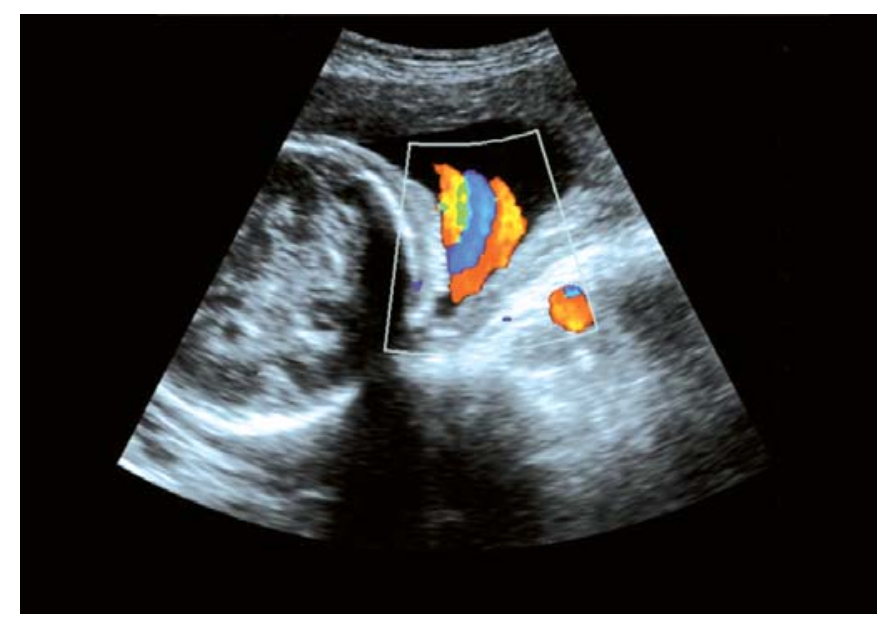

Fig. 4: Nuchal cord

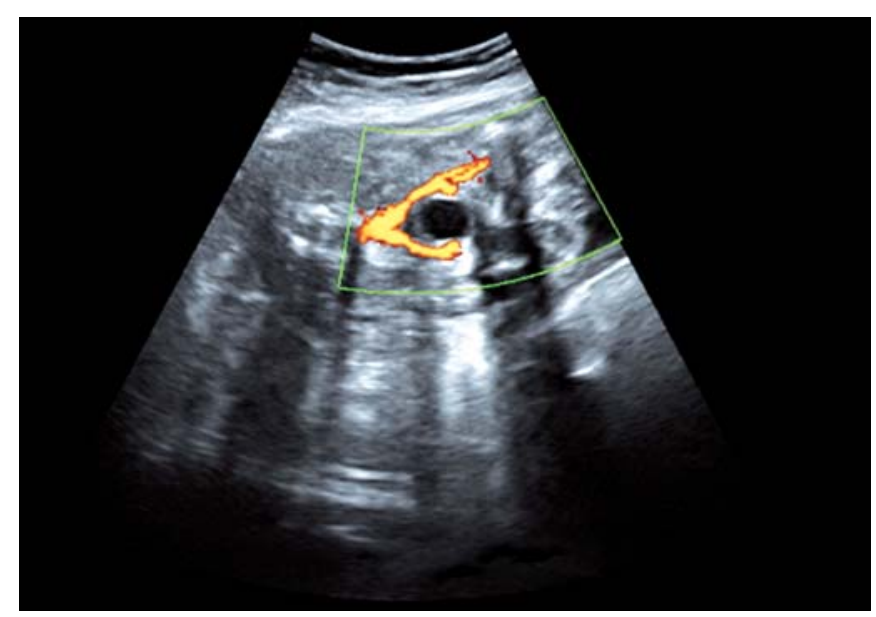

Fig. 5: Supra-vesical arteries

\section{Single Umbilical Artery}

- Single umbilical artery is diagnosed at the fetal end of the cord and not at the placental end, where it could be a normal variation due to fusion of two arteries.

- Ultrasonographically single umbilical artery is diagnosed by identifying the superior-vesical arteries (Fig. 5) skirting the fetal bladder.

Single umbilical artery is associated with:

1. Cardiovascular abnormalities of the fetus.

2. Genitourinary abnormalities of the fetus.

3. Growth restricted fetuses.

4. It may be a normal variation.

Absence of fetal bladder in between the superior vesical arteries is suggestive of Potter syndrome.

\section{Varix or Aneurysm of Intra-abdominal Part of Umbilical Vein (Fig. 6)}

- Varix of the umbilical vein can be extra-abdominal or intraabdominal. 

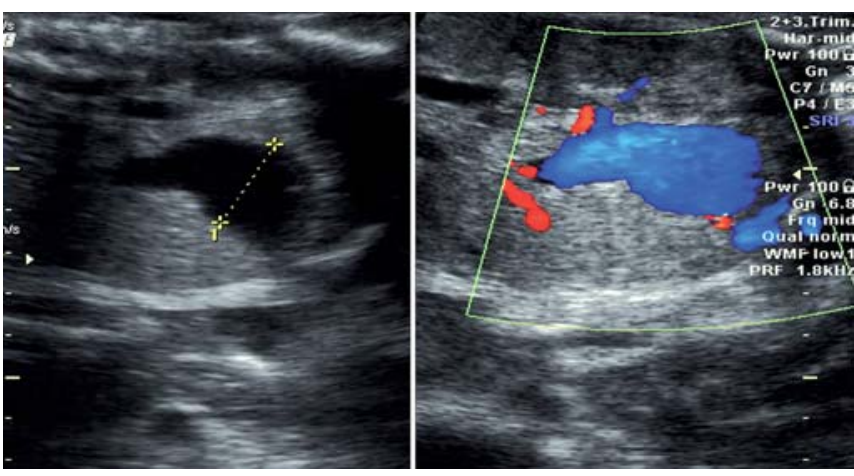

Fig. 6: Varix of intra-abdominal umbilical vein

- Extra-abdominal varix is associated with vascular compromise secondary to thrombosis.

- Intra-abdominal varix was initially thought to be associated with fetal anomalies with poor fetal outcome but present thinking is that it has normal outcome.

\section{Abnormal Course of Umbilical Vein, Persistent Right Umbilical Vein (Fig. 7)}

- There are two umbilical veins during the embryonic development.

- The right umbilical vein atrophies and the left umbilical vein persist.

- Normally the intrahepatic umbilical vein is located medial to the gallbladder and the portal vein turns away from the stomach.

- Persistent right umbilical vein sonographically appears with the intrahepatic umbilical vein lateral to the gallbladder, and the portal vein turns towards the stomach.

\section{Absence of Ductus Venosus}

- Normally ductus venosus connects the umbilical vein and the portal vein to the IVC.

- Absence of the ductus venosus results in direct connection of the umbilical vein to the right atrium, inferior vena cava or iliac vein.

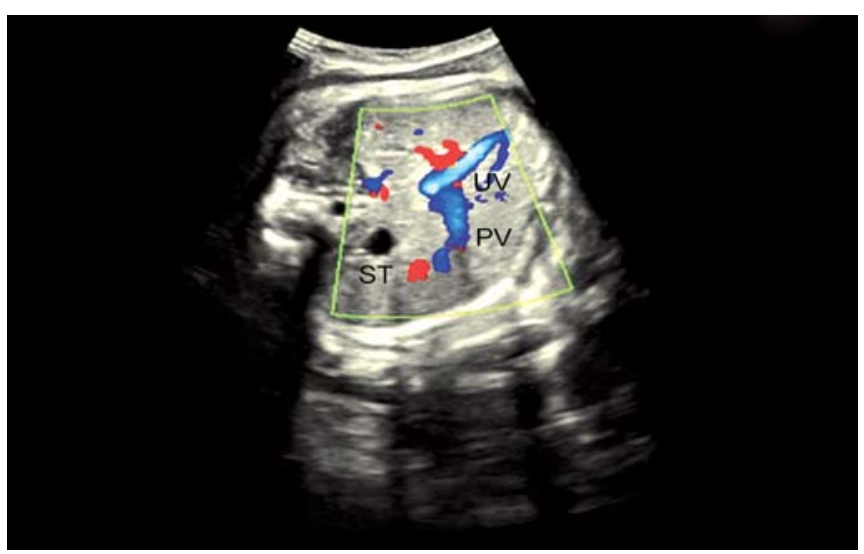

Fig. 7: Persistent right umbilical vein
- Its absence usually causes hydrops fetalis and is associated with high mortality rate, chromosomal anomalies and congenital malformations.

- Congenital anomalies like facial clefts, hemivertebrae, cardiac, genitourinary, gastrointestinal anomalies are associated with the absence of ductus venosus.

- In this condition, the umbilical vein always drains directly into right-sided structures such as inferior vena cava or right atrium.

\section{Monochorionic Twins}

Color Doppler is useful in:

- Identification of placental vascular communications in twinto-twin transfusion syndrome (TTTS) (Fig. 8A).

- Detection of retrograde perfusion in twin reversed arterial perfusion (TRAP) sequence.

- Diagnosis of cord entanglement in monoamniotic twins (Fig. 8B).

\section{Renal Vessels (Figs 9 to $10 \mathrm{C}$ )}

Color Doppler helps in the diagnosis of renal abnormalities, such as:

- Unilateral or bilateral renal agenesis

- Accessory renal vessels

- Horse shoe kidney

- Pelvic kidney.

\section{Intracranial Vessels}

Color Doppler helps in the diagnosis of abnormalities based on features such as:

- Intracranial arteriovenous malformations (Fig. 11)

- Abnormal course of the vessels

- Abnormal shape or distorted “Circle of Willis” (Fig. 12). Intracranial malformations such as vein of Galen Aneurysm can be differentiated from arachnoid cyst, porencephaly, and hydrocephaly (Fig. 13).

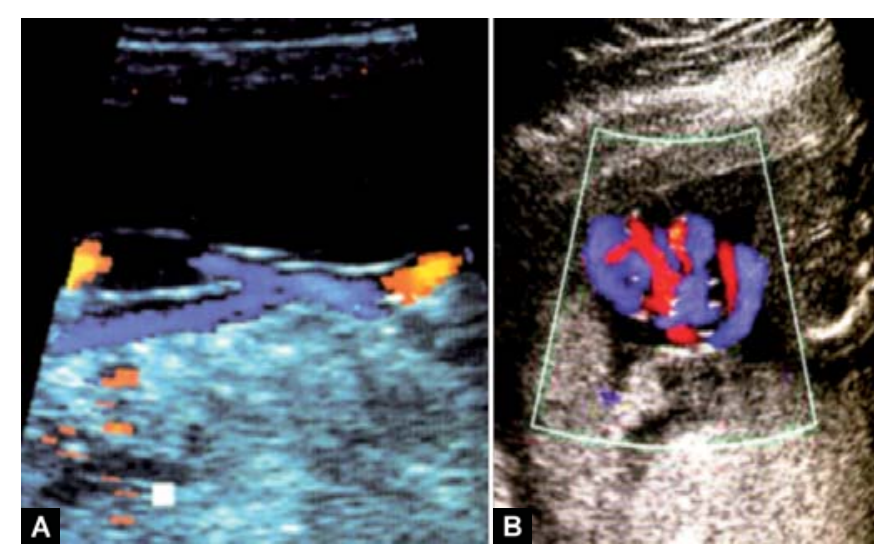

Figs 8A and B: (A) Bridging vein in TTTS (B) Entangled cord 


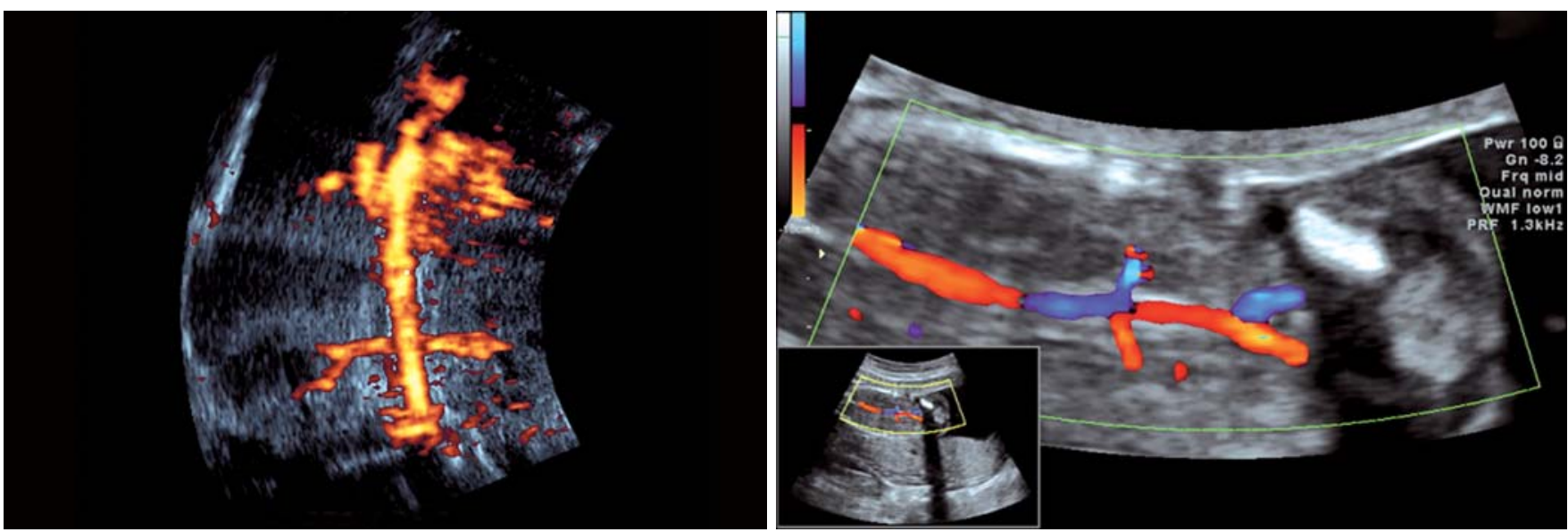

Fig. 9: Normal abdominal aorta and its branches
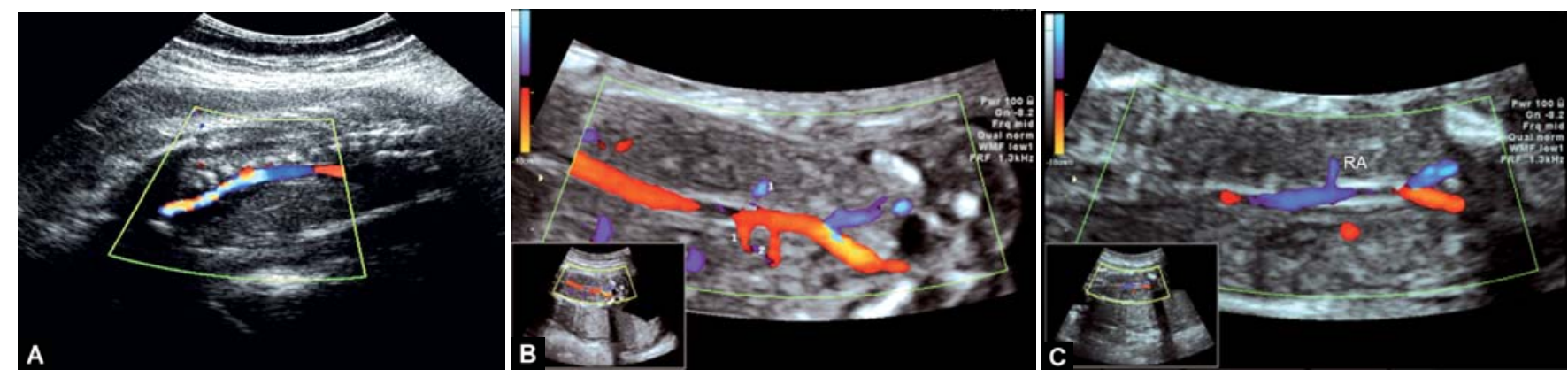

Figs 10A to C: $(A)$ Absent renal artery, $(B)$ accessory renal arteries, $(C)$ unilateral renal agenesis

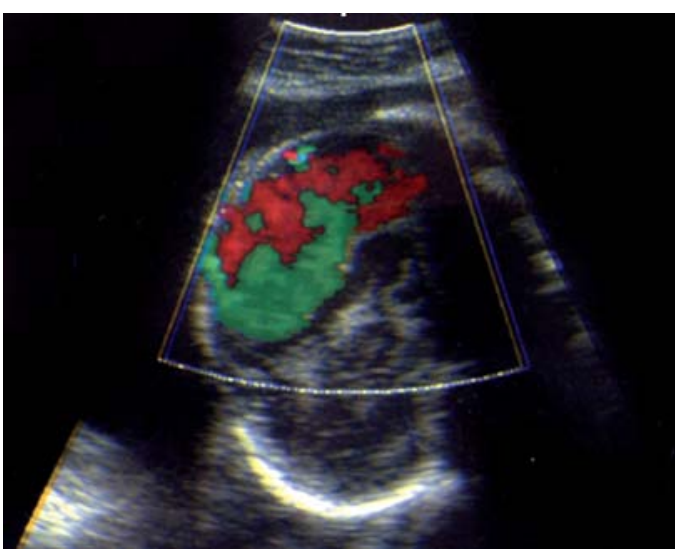

Fig. 11: AV malformation in the brain

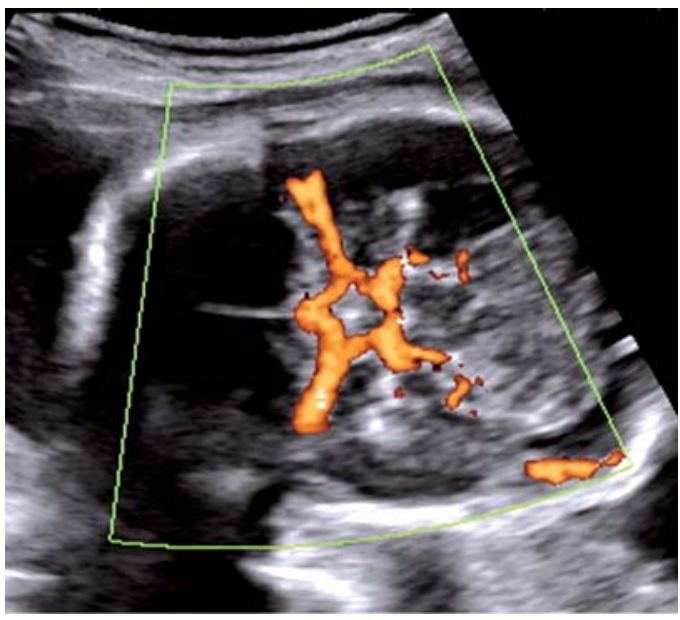

Fig. 12: Circle of Willis (Normal)

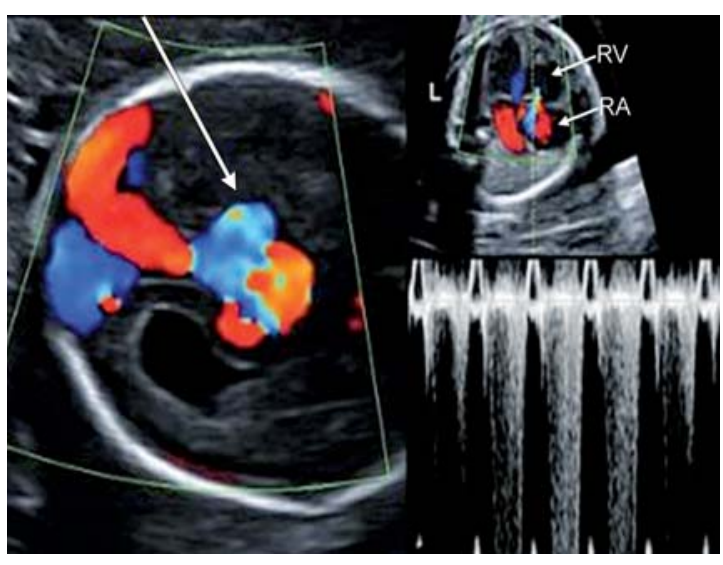

Fig. 13: Vein of Galan aneurysm

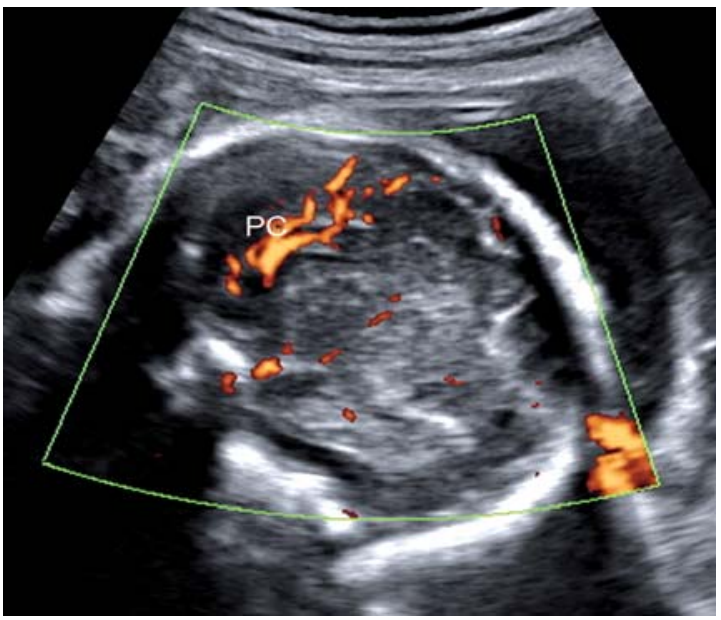

Fig. 14: Pericollosal artery 
Agenesis or dysgenesis of the corpus callosum is associated with an abnormal looping of the pericallosal artery (Fig. 14).

In microcephaly and holoprosencephaly, the shape of the Circle of Willis may be distorted.

\section{Thoracic Lesions}

- Color Doppler helps in evaluating and confirming certain thoracic lesions.

- Sampling of the pulmonary arteries and veins helps in identifying pulmonary hypoplasia and unilateral agenesis.

- Identification of liver vessels in the thorax confirms the diagnosis of right-sided congenital diaphragmatic hernia (CDH) (Fig. 15).

- Demonstration of systemic blood supply from the descending aorta to the lung confirms sequestrated lung (Fig. 16).

\section{Color Doppler in Intra-abdominal Lesions}

- Color Doppler is necessary to demonstrate the attachment of the umbilical cord and to help distinguish between omphalocele and gastroschisis (Fig. 17).

- Color Doppler helps in identifying the contents of exompholus, which in turn helps in prognostication.

- Fetus with left isomerism (polysplenia) — a cross-section in the upper abdomen shows stomach on the right side, absence of inferior vena cava and dilated azygous vein near the aorta. In the longitudinal coronal view, different flow directions in the aorta and azygous vein are demonstrated by color Doppler.

\section{Fetal Tumors (Figs 18 to 20)}

- Fetal tumors are rare.

- Precise description and information regarding its vascularity is essential for planning perinatal management of these lesions.

- Fetal goiter shows high perfusion in the thyroid gland.

- Color Doppler helps in differentiating renal from suprarenal tumors.

- Color Doppler is also useful in the distinction of sacrococcygeal teratoma, which is vascular from other cystic lesions, such as meningocele or ectodermal cyst.

\section{Visualization of Fluid Movement}

- Color Doppler not only helps in visualization of blood flow but also helps in identifying fluid movement.

- During normal fetal breathing movements, flow can be observed at the level of the mouth, nose and trachea.

- Flow has been shown to be decreased in those fetuses with diaphragmatic hernia and lethal pulmonary hypoplasia.

- In laryngeal atresia, there is no fluid flow within the dilated trachea.

- In fetuses with duodenal stenosis or atresia, to and fro fluid movements can be observed within the stomach, which presumably represents abnormal peristaltic movements (Fig. 21).

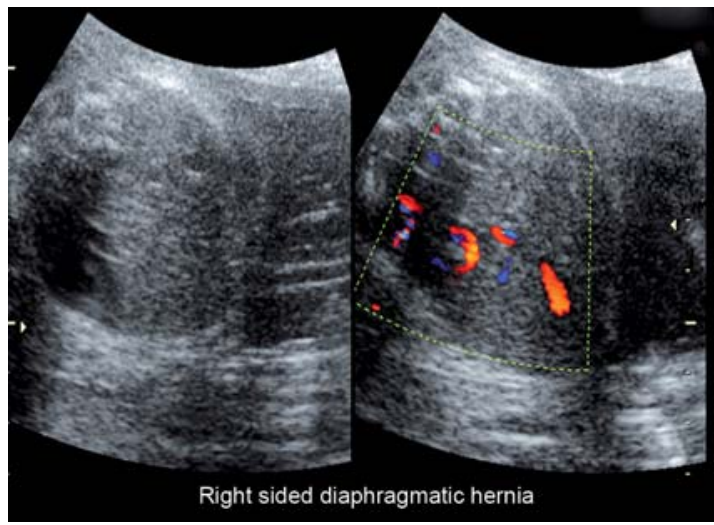

Fig. 15: Liver vessels in the thorax (Right $\mathrm{CDH})$

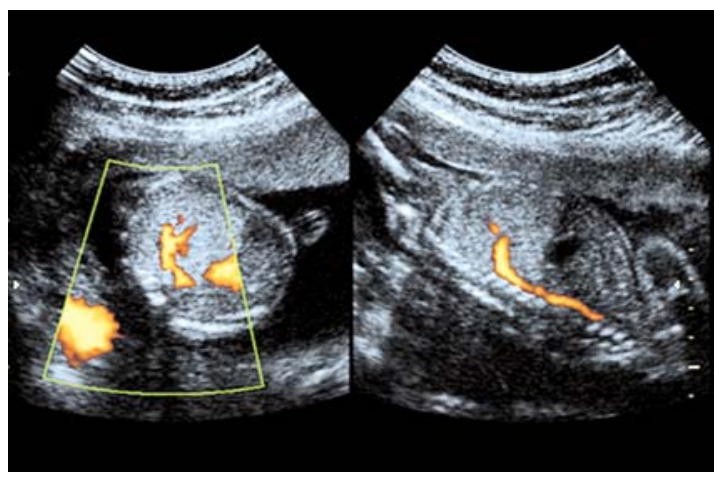

Fig. 16: Sequestrated lung systemic art supply

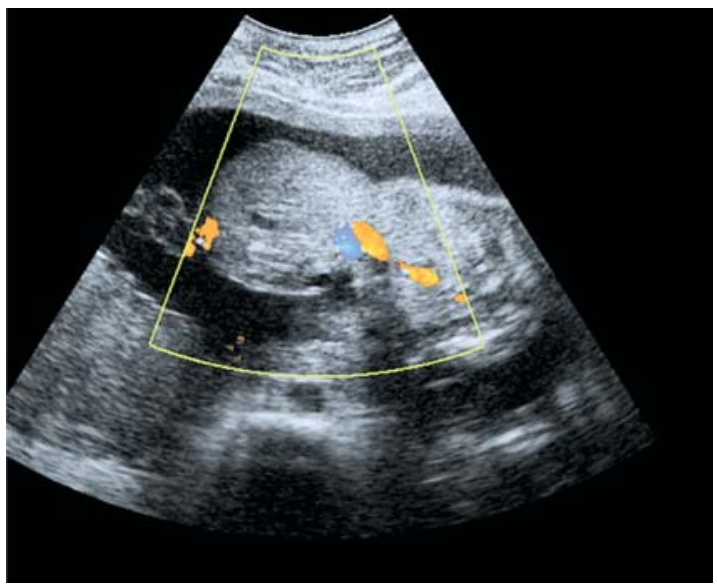

Fig. 17: Paraumbilical hernia of liver

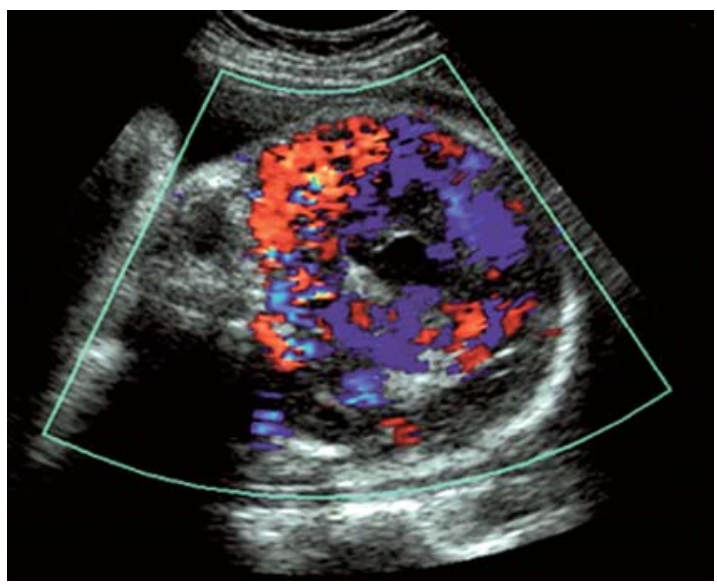

Fig. 18: Intracranial tumor 


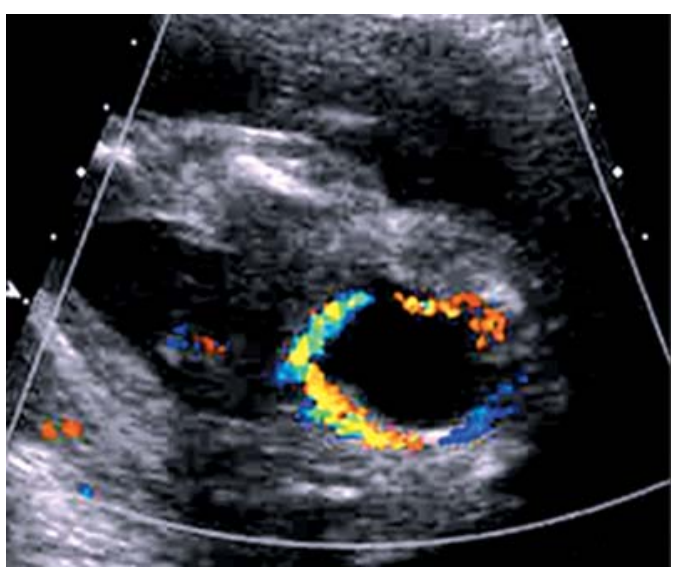

Fig. 19: Differentiating ovarian cyst from bladder

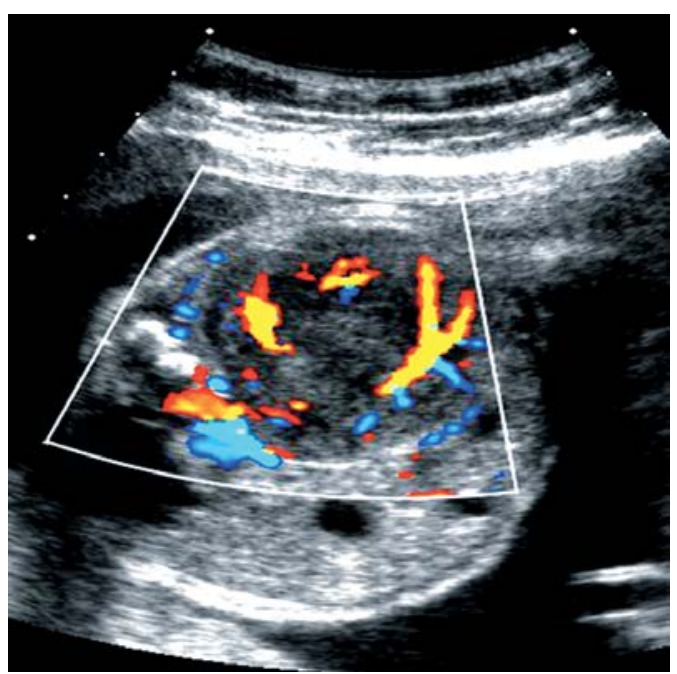

Fig. 20: Highly vascular renal tumor

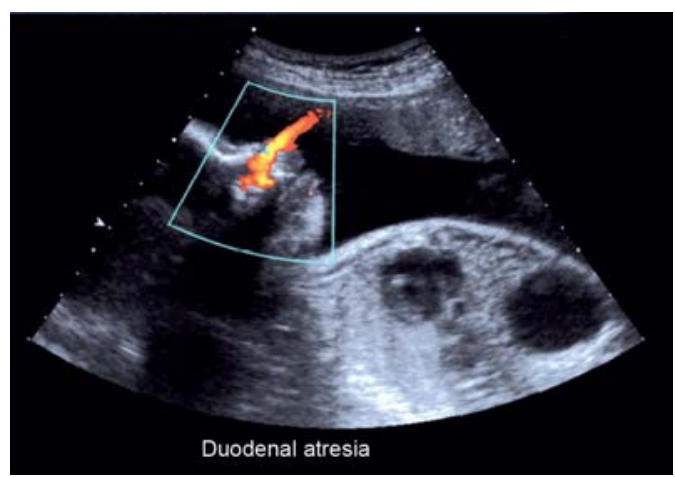

Fig. 21: Fetal vomiting

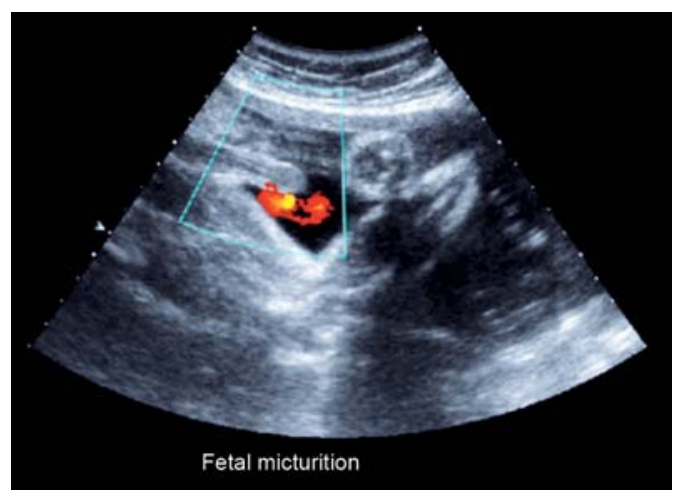

Fig. 22: Fetal urination
- Color Doppler helps in the diagnosis of vesicoureteric reflux.

- Genital abnormalities of the fetuses can be diagnosed by visualizing fetal micturition (Fig. 22).

\section{Color Doppler in Oligohydramnios}

Three main causes of oligohydramnios:

1. Premature rupture of membranes

2. Bilateral renal agenesis or dysplasia

3. Fetal hypoxia with IUGR.

In premature rupture of membranes, renal vessels are normal, umbilical flow and filling of the bladder are normal.

Bilateral renal agenesis is diagnosed by demonstrating the absence of renal arteries on both sides from the abdominal aorta.

Fetal hypoxia is diagnosed by demonstrating renal arteries and indicating increased flow resistance in the fetal circulation.

\section{REFERENCES}

1. Chaoui R, Kalache K, Bollmann R. Three-dimensional color power angiography in the assessment of fetal vascular anatomy under normal and abnormal conditions. In Kupesic S, Kurjak A, eds. Three-dimensional power Doppler in obstetrics and gynecology. Carnforth, UK: Parthenon Publishing 2000; 150-58.

2. Chaoui R, Kalache K. Three-dimensional color power imaging: principles and first experience in prenatal diagnosis. In Merz E, (Ed). 3D Ultrasonography in Obstetrics and Gynecology. Philadelphia: Lippincott, Williams and Wilkins, 1998;135-42.

3. Di Salvo DN, Benson CB, Laing FC, Brown DL, Frates MC, Doubilet PM. Sonographic evaluation of the placental cord insertion site. Am J Roentgenol 1998;170:1295-98.

4. Arts H, van Eyck J. Antenatal diagnosis of vasa previa by transvaginal Color Doppler sonography. Ultrasound Obstet Gynecol 1993;3:276-78.

5. Vickie A Feldstein, Robert D Harris, Geoffrey A Machin. Ultrasound evaluation of the placenta and umbilical cord. Ultrasonography in Obstetrics and Gynecology. Peter G Cllen 721-57.

6. Chou MM, Ho ESC, Lu F, Lee YH. Prenatal diagnosis of placenta previa/accreta with Color Doppler ultrasound. Ultrasound Obstet Gynecol 1992;2:293-96.

7. Persutte WH, Hobbins J. Single umbilical artery: A clinical enigma in modern prenatal diagnosis. Ultrasound Obstet Gynecol 1995;6:216-29.

8. Hill LM, Mills A, Peterson C, Boyles D. Persistent right umbilical vein: Sonographic detection and subsequent neonatal outcome. Obstet Gynecol 1994;84:923-25.

9. Hecher K, Ville Y, Nicolaides KH. Color Doppler ultrasonography in the identification of communicating vessels in twin-twin transfusion syndrome and acardiac twins. J Ultrasound Med 1995;14:37-40.

10. Mackenzie FM, Kingston GO, Oppenheimer L. The early prenatal diagnosis of bilateral renal agenesis using transvaginal sonography and Color Doppler ultrasonography. J Ultrasound Med 1994;13:49-51.

11. Dan U, Shalev E, Greif M, Weiner E. Prenatal diagnosis of fetal brain arteriovenous malformation: The use of Color Doppler imaging. J Clin Ultrasound 1992;20:149-51.

12. Guzman ER, Walters C, Sharma S, Tierney R, Palermo A, Vintzileos AM. Two-dimensional gray-scale imaging and Color Doppler in the detection of the corpus callosum and pericallosal artery. Ultrasound Obstet Gynecol 1999;14:53. 
13. Botash RJ, Spirt BA. Color Doppler imaging aids in the prenatal diagnosis of congenital diaphragmatic hernia. J Ultrasound Med 1993;12:359-61.

14. Morin L, Crombleholme TM, Louis F, D’Alton ME. Bronchopulmonary sequestration: Prenatal diagnosis with clinicopathologic correlation. Curr Opin Obstet Gynecol 1994;6:479-81.

15. DM, Fromberg RA, Rindfusz DW, Harris BH, Sanz LE. Color Doppler aided prenatal diagnosis of a type 1 cystic sacrococcygeal teratoma simulating a meningomyelocele. Am J Perinatol 1997;14:13-15.
16. Bruner JP, Coggins T. Assessment of fetal breathing movements using three different ultrasound modalities. J Clin Ultrasound 1995;23:551-53.

17. Kalache KD, Chaoui R, Bollmann R. Doppler assessment of tracheal and nasal fluid flow during fetal breathing movements: Preliminary observations. Ultrasound Obstet Gynecol 1997;9:257-61.

18. Kalache KD, Chaoui R, Hartung J, Wernecke KD, Bollmann R. Doppler assessment of tracheal fluid flow during fetal breathing movements in cases of congenital diaphragmatic hernia. Ultrasound Obstet Gynecol 1998;12:27-32. 